\title{
A RARE CASE OF CUTANEOUS BOTRYOMYCOSIS- A CASE REPORT AND REVIEW OF LITERATURE
}

\author{
Vidyadhar A. Kinhal1, Vishwakumar K. $S^{2}$
}

1 Professor and HOD, Department of General Surgery, VIMS, Bellary.

2 Postgraduate Student, Department of General Surgery, VIMS, Bellary.

HOW TO CITE THIS ARTICLE: Kinhal VA, Vishwakumar KS. A rare case of cutaneous botryomycosis- a case report and review of literature. J. Evolution Med. Dent. Sci. 2017;6(40):3197-3198, DOI: 10.14260/Jemds/2017/691

\section{PRESENTATION OF CASE}

A forty years old man presented with complaints of multiple nodules and discharging sinuses, following a minor trauma on back of the leg, since six months. Vital signs and systemic examinations were normal. Local examination revealed nodular, cystic, tender lesions, multiple discharging sinuses which were fixed to underlying muscles with induration of surrounding skin [Fig. 1]. Investigations showed $\mathrm{Hb}$ of 12.6 gm\%, TLC of 8,500 cells $/ \mathrm{mm} 3$ and ESR was $45 \mathrm{~mm} / \mathrm{hr}$. Random blood sugar, Renal function tests, Chest and leg $\mathrm{x}$ rays were normal and his serum was non-reactive to HIV. Discharge from the lesion showed pus cells and gram positive cocci in clusters and no fungal element. Culture revealed polymicrobial pattern and no fungal growth. Fine needle aspiration was suggestive of acute inflammatory lesion.

\section{DIFFERENTIAL DIAGNOSIS}

Keeping in mind the possibility of actinomycosis or botryomycosis, he has been given two weeks course of broadspectrum antibiotics for which he did not respond. Taking into account of the chronicity of the lesion, non-response to antibiotics, total excision of lesion was done and wound was left to granulate.

\section{CLINICAL DIAGNOSIS}

Histopathological examination revealed tissue fragments lined by stratified squamous epithelium with stroma exhibiting cystic spaces surrounded by dense mixed inflammatory cell infiltrate along with inflammatory granulation tissue. Central area of the cystic spaces contain granular, basophilic, filamentous material surrounded by Splendore-Hoeppli Phenomenon along with neutrophilic microabscesses suggestive of botryomycosis [Fig. 2].

\section{PATHOLOGICAL DISCUSSION}

Botryomycosis was originally discovered by Otto Bollinger in 1870 , in a horse as a post-castration complication.[1] But the name was coined by Sebastiano Rivolta in 1884, which refers to its grapelike granules (Gr. botryo = bunch of grapes, mykes = fungus) and the mistakenly implied fungal aetiology.[2,3] In 1919 , first paper was published on botryomycosis in humans. In contrary to initial thoughts it stated Staphylococcus aureus as the aetiological agent and the granules were not composed of mycotic masses, but were the bacteria that adhered to each other.[1]

Financial or Other, Competing Interest: None.

Submission 11-04-2017, Peer Review 04-05-2017,

Acceptance 11-05-2017, Published 18-05-2017.

Corresponding Author:

Dr. Vishwakumar K. S,

\#10, New PG Boys Hostel, VIMS, Ballari.

E-mail: vishwakumarkaranth@gmail.com

DOI: $10.14260 /$ jemds $/ 2017 / 691$

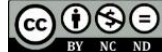

Botryomycosis (or bacterial pseudomycosis or pyoderma vegetans) is a rare chronic, granulomatous, suppurative bacterial infection which has cutaneous and visceral forms.[15] The primary cutaneous form is most common and presents with nodules, abscesses and multiple sinuses or fistulae with serous or purulent discharge with or without granules. ${ }^{[1-2]}$ It heals with fibrosis usually after a long course antibiotics. ${ }^{[4]}$ Visceral form usually involves the lung and is associated with cystic fibrosis. ${ }^{[2,3]}$

Botryomycosis can be caused by multiple bacteria, but most commonly it involves S. aureus (40\%) and Pseudomonas aeruginosa (20\%).[1] Other organisms attributed are Micrococcus pyogenes, Streptococcus, Escherichia coli, Staphylococcus epidermidis, Proteus vulgaris and Propionibacterium acnes.[1,6] However, multibacterial aetiology in a single patient is rarely detected.[2]

The pathogenesis of botryomycosis is not completely understood. However, it is associated with defective cellular immunity.[1] It requires a balance between the number of microorganisms inoculated during trauma, their low virulence and the host's tissue response.[1,6] The predisposing factors are diabetes, liver disorders, steroids use, alcoholism and cystic fibrosis, bronchial asthma, malnutrition, AIDS, etc., which are usually associated with impaired immunity.[1,4,6]

The skin lesions are indistinguishable from that of actinomycosis and eumycetoma, and its granules which are caused by masses of colonising bacteria, resemble the sulphur granules of actinomycosis.[1,6] Other differential diagnosis includes tuberculosis and chronic abscesses.[1] The lesions usually occurs on extremities, the head and neck, buttocks are rarely involved.[2,6]

Histopathologic examination of botryomycosis shows a marked inflammatory response, scarring and suppuration.[6,7] Transepidermal elimination and marked epithelial hyperplasia may be seen. The sulphur granules of botryomycosis contain clusters of blue stained bacteria surrounded by an intensely eosinophilic coat with club-like projections.[6,7] This typical histologic appearance is referred to as the Splendore-Hoeppli phenomenon and can be seen using gram stain, Giemsa stain, PAS stain or silver stain. [7,3]

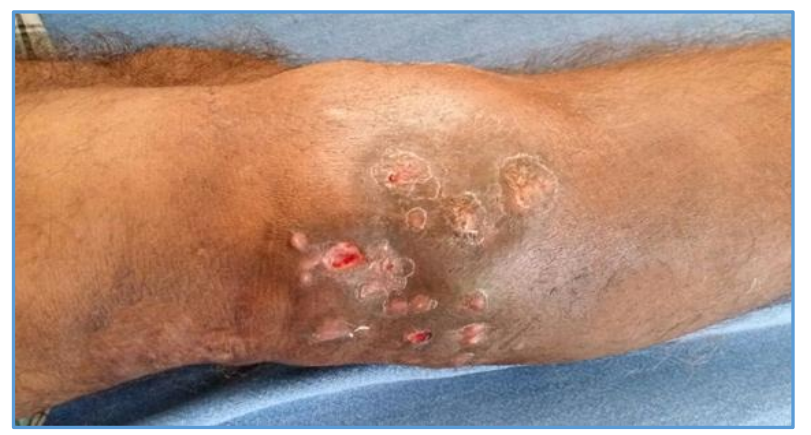

Figure 1. Multiple Nodules and Discharging Sinuses on Back of the Leg 


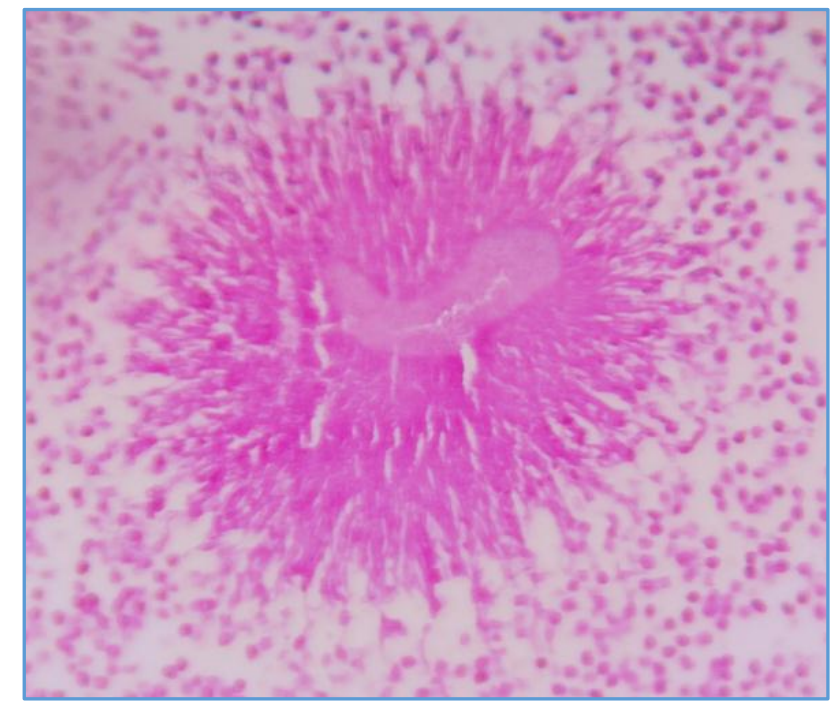

Figure 2. Histopathological View showing Splendore-Hoeppli Phenomenon

\section{DISCUSSION OF MANAGEMENT}

Botryomycosis is treated with long-term antibiotics depending on the bacteria identified, culture and sensitivity report.[4,7] Surgical drainage and debridement or Laser vaporisation may be required in long-standing and unresponsive cases. ${ }^{[7,8]}$ In this patient since entire lesion was already excised and wound granulated well, which was covered with split skin graft three weeks later.

Botryomycosis is a rare chronic, granulomatous, suppurative, bacterial infection which can involve the skin and the viscera. The skin lesion typically presents with multiple purulent discharging sinuses, which are often confused with the eumycetoma or actinomycosis. The only way of accurate diagnosis is demonstration of typical histological features on microscopy and establishment of causative organism by culture. The common causative organisms attributed are Staphylococcus aureus, Escherichia coli and Pseudomonas aeruginosa. Even though it is associated with impaired immunity, cases have been reported in patients with normal immune function and its pathogenesis is still poorly understood.

\section{FINAL DIAGNOSIS}

Cutaneous botryomycosis is a rarely reported entity in literature and pathogenesis of which is incompletely understood. High degree of clinical suspicion and typical histological features are important factors in the diagnosis.

\section{REFERENCES}

[1] Makama JZ, Khan N, Makhanya NZ. Botryomycosis-case report. SA Journal of Radiology 2006;14-5.

[2] Devi B, Behera B, Dash ML, et al. Botryomycosis. Indian J Dermatol 2013;58(5):406.

[3] Bhatti MA, Almagro UA, Sohnle PG. Primary pulmonary botryomycosis. Infect Med 2002;19(4).

[4] Srivastava M. Botryomycosis due to staphylococcus aureus-a case report. International Journal of Recent Trends in Science And Technology 2014;10(3):436-7.

[5] James WD, Berger TG, Elston DM. Bacterial infections. $11^{\text {th }}$ edn. Andrew's diseases of the skin. Clinical Dermatology. Elsevier 2011:pp 250.

[6] Katkar V, Mohammad F, Raut S, et al. Red grain botryomycosis due to staphylococcus aureus-a novel case report. Indian J Med Microbiol 2009;27(4):370-2.

[7] Emanuel P. Botryomycosis pathology. DermNet NZ. Dermatopathologist, Auckland, New Zealand, 2013.

[8] Leffell DJ, Brown MD, Swanson NA. Laser vaporization: a novel treatment of botryomycosis. The Journal of Dermatologic Surgery and Oncology 1989;15(7):703-5. 